\title{
Importance of Energy Audit in Diesel Engine Fuelled with Biodiesel Blends: Review and Analysis
}

\author{
Sanjay Mohite ${ }^{1,2 *}$, Sagar Maji ${ }^{3}$
}

\author{
'Department of Mechanical Engineering, National Institute of Technology, Kurukshetra, Haryana, INDIA \\ ${ }^{2}$ Department of Mechanical Engineering, Brahma Valley College of Engineering \& Research Institute, Nashik, INDIA \\ ${ }^{3}$ Department of Mechanical Engineering, Delhi Technological University, New Delhi, INDIA \\ 'Corresponding Author: smohite001@yahoo.com
}

Citation: Mohite, S., \& Maji, S. (2020). Importance of Energy Audit in Diesel Engine Fuelled with Biodiesel Blends: Review and Analysis. European Journal of Sustainable Development Research, 4(2), em0118. https://doi.org/10.29333/ejosdr/7596

\section{ARTICLE INFO}

Received: 9 Jun. 2019

Revised: 30 Dec. 2019

Accepted: 30 Dec. 2019

\begin{abstract}
Number of experiments have been performed on various performance and emission characteristics, effect of biodiesel blends on lubricity and input and output energy distribution in diesel engine fuelled with biodiesel blends. It is also reviewed that energy audit is used in buildings, plants, process and equipments and energy audit method was developed for fishing vessels based on similar systems for land based industries. In land based businesses, industries and households, energy audits are presently used to investigate the use of energy and to identify opportunities for the efficiency improvement and effectiveness in the energy use. Energy audits have been used in various sectors, industries and utilities. This paper is a review paper of energy audit and it is found that there is a vast scope for implementation of standardized energy audit in diese engines fuelled with biodiesel blends. Its objective is to find out a standard energy audit method for diesel engine fuelled with biodiesel blends which evaluate the feasibility of biodiesel blend as fuel and also harmonise the research of biodiesel as fuel.
\end{abstract}

Keywords: energy audit, biodiesel blends, diesel engine, performance and emission characteristics, heat flow analysis

\section{ABBREVIATIONS}

$\begin{array}{ll}\text { A/F Ratio } & \text { : Air Fuel Ratio } \\ \text { BSEC } & \text { : Brake Specific Energy Consumption } \\ \text { BSFC } & \text { : Brake Specific Fuel Consumption } \\ \text { BTE } & \text { : Brake Thermal Efficiency } \\ \text { EGT } & \text { : Exhaust Gas Temperature } \\ \text { JB } & \text { : Jatropha Biodiesel } \\ \text { KB } & \text { : Karanja Biodiesel } \\ \text { PB } & \text { : Polanga Biodiesel }\end{array}$

\section{INTRODUCTION}

It is reported that an energy audit is used to find out energy use within a structure, plant, process or equipment system and also investigate the energy conservation. The first step of energy audit is the determination of the ways in which energy is consumed, which includes how, what, when, where, why and how much quantity of energy is consumed. If consumption of energy is found out, then, it is simpler to investigate methods to reduce energy consumption with improved management, efficiency and conservation (Parker, 2015).

The latest concept of the energy audit is to focus on the strategy of cost effectiveness towards energy conservation with the considerations of energy costs, government regulations, new technologies, environmental concerns and emerging services in business. Residential, commercial and industrial types of facility are auditable. The audit can be applied to a facility or it can be applied on a focus area of the structure, specified equipments, isolated processes and systems. Energy audit's scope may include electric, gas, oil, water and sewage etc. types of utility services. The audit of refrigerants, boilers emissions and chemical process 
application may include impact parameters of environment. All types of energy audits comprise of data collection, data analysis and recommendations. Energy audits can be generally classified into three categories (Braquet, 1999):

1. Walk through audit which means simple audit, preliminary audit or screening audit.

2. Site Energy Audit which means mini-audit, general audit, complete site audit.

3. Comprehensive Audit which means detailed audit or technical analysis audit.

Energy audits are designed to get the information of energy conservation opportunities. Preliminary survey is the first step of energy audit. Energy consumption indices or performance characteristics for the consumer group under study can be computed with the help of design survey instrument. The objective is not to develop an analytical model which consider all the variable which influence energy consumption. The objective is to make a simple survey instrument to take appropriate measures (Turley \& Bui, 1981). Researchers defined energy audit as a process of evaluation of use of energy in a building and identify scope for the energy consumption reduction (Thumann \& Younger, 2010). Energy audit data is used to offer an optimum combination of hybrid renewable energy systems resulting in reduction of dependency on diesel fuel for the island (Khan et al., 2016).

At the initial stage, a standard energy audit method is required to evaluate the feasibility of biodiesel blend as fuel in diesel engine. If biodiesel blend is found suitable, detail energy audit can be done further. If biodiesel blend is not found suitable at primary stage of energy audit, further consideration of blend as fuel is not required which saves time and money. The objective of this study is to find out the importance of Energy Audit in Diesel engine fuelled with Biodiesel blends. This research is being done to identify the scope of energy audit in evaluation of diesel engine fuelled with biodiesel blends. In this research and analysis paper, it is found that a standardised energy audit is required to harmonise the research of biodiesel as fuel. In this paper, some important parameters have been selected to include it in standard energy audit. This is done on the basis of their influence on other parameters.

\section{VARIOUS APPLICATIONS OF ENERGY AUDIT}

Energy audits are effective tool which access energy use in building and also compute expenditure to save energy. In energy audits, ASHRAE determined guidelines for four levels of energy audits. Level 0: Preliminary analysis of energy use, Level 1: Walk through analysis. Level 2: Analysis and survey of energy. Level 3: Detailed analysis for capital investment decisions (Niu \& Leicht, 2016).

The traditional energy audit is just not sufficient for today's projects of energy. Traditional energy audit follows a snap shot approach which considers all present conditions static for the projected time. In investment grade audit, a component of assessment in risk is used which assesses conditions in the particular building with the consideration of human aspects (Hansen, 1999). An energy audit, which is also known as feasibility study concerns about the thorough examination of two years of utility bills, mathematical modelling of energy use when the system is supposed to operate properly, routine plant operation's review and list of upgrades with their costs of installation and savings in a building (Audin, 2002). Researchers presented a critical overview of the Infrared thermography applications in the building energy audit (Lucchi, 2018). Reseachers reported design and application of a smart energy audit which is incorporated in building. Researchers also adopted methods to detect fault in plant (Belussi et al., 2017). A good energy audit is used to make valuable decisions on the investment for the best energy efficiency. Energy audit development involves identification and communication of the best energy conservation measures (Anina \& Rottmayer, 2016). Reduction of energy consumption and impact on the environment are some of the objectives of the energy audit. Energy and environment are associated with a green energy audit. This green energy audit provides methods for the optimisation of energy performance of buildings and make them sustainable (Dall et al., 2012).

An energy audit is an important step for the improvement of energy efficiency at the facility level. An energy audit was conducted in a paper mill plant in Guangdong Province in China to identify energy conservation and opportunities for $\mathrm{CO}_{2}$ emission reduction (Kong et al., 2013). It is mandatory to implement energy audit in large companies regularly according to Energy efficiency directive of the European Commission (Nabitz \& Hirzel, 2019). Researchers conducted an energy audit which was relied on brick, refractory and insulation with its effect on efficiency and reliability of boiler and savings of fuel. Researchers concluded that if brick, refractory and insulation are not installed in a proper way, then more quantity of fuel is consumed by the boiler. Researchers has concluded that after correction and changes, a significant annual savings in energy (pulverize coal) cost is achieved (Bases, 2004).

Life cycle analysis's methodology was used to develop a model based on computer for the evaluation of energy use in the mechanised wood harvesting system. Program of visual basic was used in the computer model. Energy audit was based on consumption of fuel and oil and the energy consumption in the manufacture of the machines and replacement parts. In this energy audit, the most important parameter was fuel consumption (82\%) followed by oils (7\%) and machine repairs and replacements (11\%). An energy reduction strategy to reduce overall energy consumption upto $13 \%$ was suggested (Klvac et al., 2003).

A methodology was used for identification of opportunities to conserve energy through on-site audits of the manufacturing plants. These opportunities to conserve energy are categorised according to potential areas for savings such as motors and air compressors and are represented in view of energy savings, cost savings, implementation cost and payback period (Romero et al., 1999). Many companies realize that utilities cost can be decreased in the range of $10 \%$ to $30 \%$. Therefore, management companies and brokers of real estate, mechanical and electrical contractors and equipment dealers have tried for marketing of energy audit. An energy audit can be conducted on two different companies with a duration of 5 hours and 80 hours respectively. This type of variations implies different ideas of customers and auditors (Avina, 2013). 
When the data has put for a utility, the analysis tool would create a baseline assessment which provides an organised use of energy. The analysis tool determines a baseline of energy costs and consumption for a utility (Eisenberg, 2012). The main objective of all the data entry and the concerned software is to balance energy consumption for a facility (Cardenas- Lailhacar et al., 2005).

Compressed air is called fourth utility in industries and these air compressors are driven by electric motors. One to two weeks of detailed monitoring for equipments should be performed to check real data on compressed air flow, power, pressure and quality levels. Audit reports comprises of study, documentation, evaluation and suggestion to improve compressed air system economically (Koski, 2002).

Energy audit of a fibreboard drying production line find out that low energy efficiency is due to excessive loss of heat and lack of heat recovery. Heat may also be recovered from the exhaust, but it requires more equipments (Gong et al., 2011). Industry's operational programs such as integrity, safety, environmental protection, damage prevention, emergency management and security may be checked for their adequacy by the monitoring tool such as audit. Evaluation of the complete program can be performed with the help of comprehensive audit as a valuable tool (Mora et al., 2012).

The performance of an asset is evaluated by energy benchmarking and rating. Standardised formats defined the best in many cases. Examples of standard benchmarking and rating are energy labelling of home appliances and cars and also energy rating of the building. Researchers investigated that there were no well defined and standardised energy performance benchmarking and rating scheme for ships. Researchers introduced basic methodology, key performance indicators (KPI), their reference values and an energy rating scheme to fill the above mentioned gaps. It was investigated that proposed benchmarking and rating scheme can be used in ships, which can be used to make a difference between ships according to energy performance (Bazari, 2007).

An energy audit of a vehicle is a systematic way to assess current energy use. The purpose of the audit program is to investigate different areas for savings of fuel. The audit is an initial step in a process comprises of setting priorities to develop an energy management program. In energy audit, maintenance parameters which reduce friction losses and the parameters which affect engine performance are computed (Erkut \& Maclean, 1992).

An audit provides a base to calculate energy, $\mathrm{CO}_{2}$ emissions and financial savings which can be achieved with current technology and project the expected targets to meet Kyoto agreement or HECA legislation. It was concluded that individual audits would assess individual cities in formulating a saving of effective energy, emission reduction policy and the audits collection in a country helps their government to formulate a national approach towards energy efficiency and sustainability (Bennett \& Newborough, 2001). Energy audit helps to minimize demand and consumption of energy in industry (Bellarmine \& Arokiaswamy, 1996). It is reported that energy audit woule be a useful tool to overcome the information barriers and facilitate investments in energy efficiency measures (Kalantzisn \& Revoltella, 2019). It is reported that an energy audit would be a method to determine the most economical measures, which improves energy efficiency in an organisation (Knorring, 2019). Energy Audit is used in industries under the new law by the authorities of Morocco.The energy audit proposes a plan which has a potential for reduction of the consumption of lighting energy (Boharb et al., 2016). Problems in environment can be solved with the use of renewable energy technologies and efficient energy utilisation. Energy conservation is important for sustainable development (Dincer, 1999).

Thomas et al. (2010) investigated an energy audit method for fishing vessels based on similar systems for land based industries. They performed an energy audit for an Australian fishing vessel which recommends to improve efficiency. In land based businesses, industries and households, energy audits are presently used to evaluate the energy use and investigate opportunities for the improvement of efficiency and effectiveness in the use of energy. This energy audit investigate the field where savings can be made and recommend changes to make vessel more efficient. In this energy audit, individual vessel was analysed to investigate the use of energy in it. They proposed a sample energy audit for an Australian fishing vessel which made recommendation for efficiency improvement to reduce cost of fuel.

The efficiency, the losses of energy and the prospects for improvement in 12.8 litre heavy duty and 6.7 litre medium duty diesel engine have been analysed in the experimental work. In this experimental work, two baseline diesel engines were tested and analysed in the laboratory. Abilities of emerging technologies to reduce consumption of fuel with focus on each loss mechanism was found out with the application of energy audit and technology forecasting. Improvements in fuel consumption were investigated with improvement in the heavy duty diesel engine in this research work with the help of future technology (Thiruvengadam et al., 2014). Brief description of energy audit and items on which energy audits are implemented are listed in Table 1.

There are various investgations made by researchers in their respective studies. Some general observations which can be investigated from the literature are as follows:

Energy audit is used in various buildings, plants, process and machines. An energy audit method was developed and used for fishing vessels based on similar systems for land based industries. In land based businesses, industries and households, energy audits are presently used to find out the energy use and to identify opportunities for the improvement in efficiency and effectiveness in the energy use.

Efficiency, energy losses and the prospects for improvement in heavy duty and medium duty diesel engine have been investigated in the experimental work. In the experimental work, it is also concluded that the emerging technologies were used to improve efficiency including higher compression ratio, optimised controls, improvements in EGR, low friction lubricants, decrease in engine friction, decrease in parasitic load, improvements in turbocharging, fuel injection, design of optimized cylinder head and waste heat recovery system. These engine efficiency's emerging technologies have the ability to decrease fuel consumption significantly (Thiruvengadam et al., 2014). Various applications are energy audit are illustrated in Figure 1. 
Table 1. Energy audit application

\begin{tabular}{|c|c|c|c|}
\hline S. No & Brief description of energy audit & Items on which energy audit implemented & References \\
\hline 1 & Energy audit & Island & Khan et al. (2016) \\
\hline 2 & $\begin{array}{c}\text { Energy audit } \\
\end{array}$ & Building & Thumann \& Younger (2010) \\
\hline 3 & $\begin{array}{c}\text { ASHRAE determined guidelines for four levels of } \\
\text { energy audits }\end{array}$ & Building & Niu \& Leicht (2016) \\
\hline 4 & Investment grade audit & Building & Hansen (1999) \\
\hline 5 & Feasibility study & Building & Audin (2002) \\
\hline 6 & Energy audit & $\begin{array}{c}\text { Valuable decisions on the investment for the best } \\
\text { energy efficiency }\end{array}$ & Anina \& Rottmayer (2016) \\
\hline 7 & Green energy audit & Building & Dall et al. (2012) \\
\hline 8 & $\begin{array}{l}\text { Identify energy conservation and opportunities } \\
\text { for } \mathrm{CO}_{2} \text { emission reduction }\end{array}$ & Paper mill plant & Kong et al. (2013) \\
\hline 9 & $\begin{array}{c}\text { Energy audit } \\
\end{array}$ & Boiler & Bases (2004) \\
\hline 10 & On-site audits & Manufacturing plants & Romero et al. (1999) \\
\hline 11 & Energy audits & Companies & Avina (2013) \\
\hline 12 & Energy audits & Utility & Eisenberg (2012) \\
\hline 13 & Balance energy consumption & Facility & Cardenas- Lailhacar et al. (2005) \\
\hline 14 & Energy audits & Compressed air & Koski (2002) \\
\hline 15 & Energy audit & Fibreboard drying production line & Gong et al. (2011) \\
\hline 16 & Comprehensive audit & Industry's operational program & Mora et al. (2012) \\
\hline 17 & Proposed benchmarking and rating scheme & Ships & Bazari (2007) \\
\hline 18 & Computerised transportation program of audit & Vehicle, transportation. & Erkut \& Maclean (1992) \\
\hline 19 & Individual audits & Individual cities & Bennett \& Newborough (2001) \\
\hline 20 & Energy audit & Industry & Bellarmine \& Arokiaswamy (1996) \\
\hline 21 & Energy audit & Industry & Boharb et al. (2016) \\
\hline 22 & Energy audit method & Fishing vessels & Thomas et al. (2010) \\
\hline 23 & Detailed energy audit analyses & Diesel engines & Thiruvengadam et al. (2014) \\
\hline
\end{tabular}

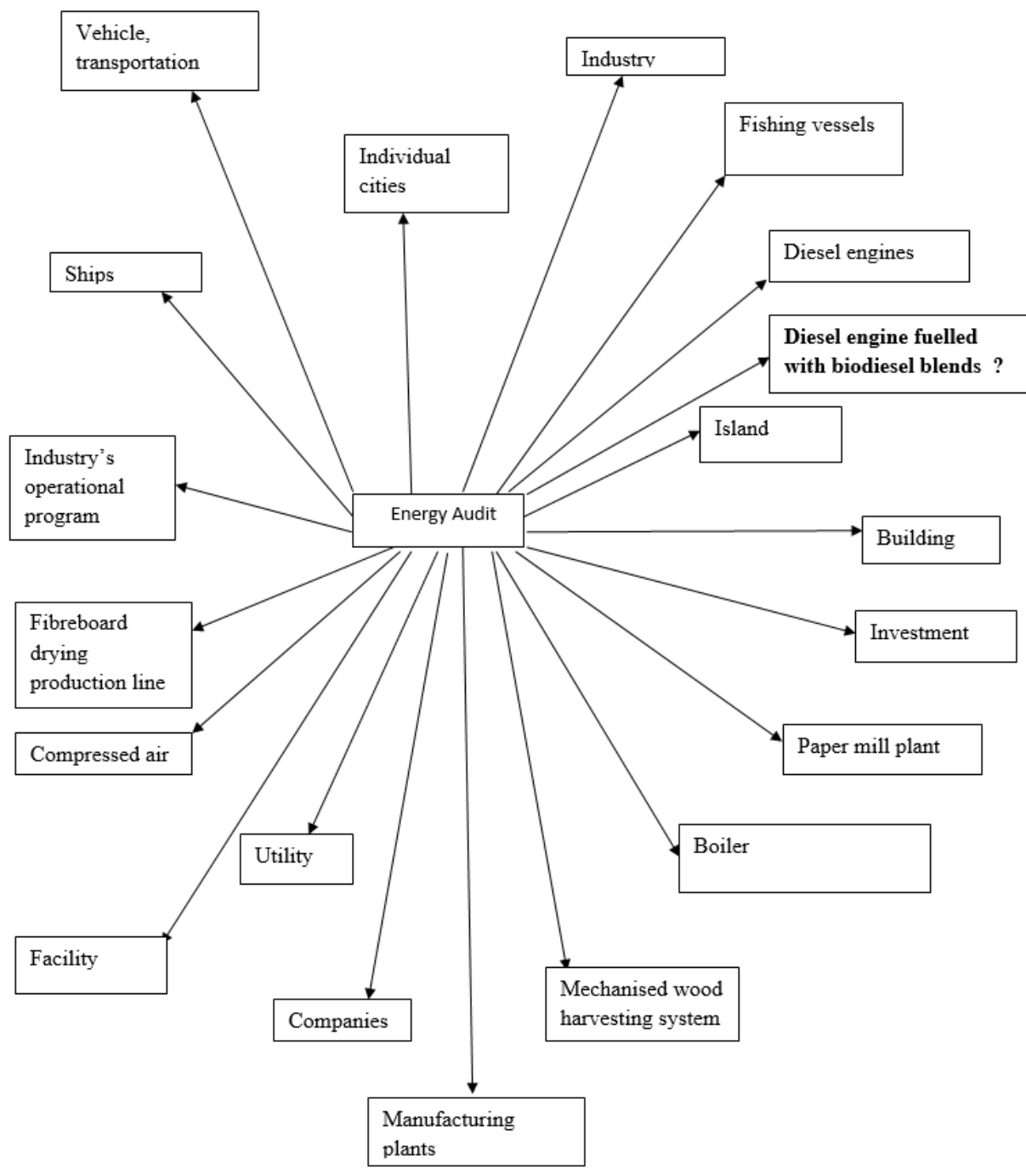

Figure 1. Various applications of energy audit 


\section{RESEARCH GAPS}

Energy audits have been used in various sectors, industries and utilities. Hence a standard energy audit method is required for diesel engine fuelled with biodiesel blends which incorporates the effect of biodiesel blends on a diesel engine with important and effective parameters and also reveals the use of fuel energy distributions in diesel engines at initial stage. At present, there is no specific reference available regarding energy audit of diesel engine fuelled with biodiesel blends.If biodiesel blend is not found suitable in energy audit, further consideration of blend as fuel is not required which saves time and money.

\section{METHODOLOGY}

The present review of energy audit is based on comprehensive literature review of energy audit regarding its applications. Research gap is found out. Various performance and emission characteristics alongwith heat flow analysis parameters have been discussed. On the basis of discussion, the important parameters have been chosen based on their effective influence on other parameters and are listed in energy audit.

\section{RESULT \& DISCUSSION}

The importance of the performance and emission characteristics of the diesel engine fuelled with biodiesel blends has been discussed in this section:

\section{Brake Thermal Efficiency (BTE)}

The ratio of work output to the quantity of fuel energy supplied is called brake thermal efficiency of an engine. It is also known as fuel conversion efficiency (Mohite et al., 2016). Higher BTE indicates better work output from the fuel energy. BTE is one of the performance parameters which indicates the quantity of transformation of chemical energy of fuel into useful work output in diesel engines. Researchers conducted tests on engine with Soybean oil biodiesel and investigated similar engine performance with methyl, ethyl and butyl esters as compared to diesel. They did not investigate much difference in thermal efficiency resulting from the use of various fuels. Slight loss of power was reported with biodiesel use which was attributed to lower heating values (Sahoo et al., 2009). Researcher reported decrease in torque with increase in Cottonseed oil biodiesel in the blends and it was attributed due to higher viscosity and lower calorific values of Cottonseed oil biodiesel (Aydin \& Bayindir, 2010). BTE decreases with the addition of biodiesel in fuel blends which may be attributed due to higher BSFC due to lower heating value of biodiesel. Higher value of BTE was investigated to be $35 \%$ for the B10 to B20 fuel blend at CR of 17.9 whereas lower BTE was reported for the fuel blend for B30 to B40 at CR of 17.7 (Sivaramakrishnan \& Ravikumar, 2014). Higher value of BTE was found to be $21.1 \%$ for B0. Higher value of BTE of 20.51\%, 20.4\%, 20.4\% and 20.3\% were found for B10, B20, B30 and B50 respectively. Lower BTE for fuel blends may be attributed due to lower calorific values and also increase in consumption of blend fuel as compared to that of diesel (EL- Kasaby \& Nemit-allah, 2013).

\section{Brake Specific Fuel Consumption (BSFC)}

BSFC is the flow rate of fuel per unit brake power output. It indicates the engine's efficiency.BSFC is found to measure the fuel efficiency of an engine. Lower value of BSFC is required. This is found to be one of the important parameter to compare while using various test fuels. The relationship between the amount of fuel injected, its density, its viscosity and its calorific values is found to play an important role in the determination of BSFC. BSFC is found to be reduced with increase in load for all fuels which may be due to increase in fuel percentage required to operate the engine and is lower than the increase in brake power percent. This is because of reduction in heat losses at higher loads. Multi-cylinder turbocharged diesel engine was tested at full load at speed of $1400 \mathrm{rpm}$. BSFC of biodiesel was $13.8 \%$ higher in comparison to diesel which was attributed due to lower calorific value of biodiesel. If the viscosity and density of biodiesel blend are higher than that of diesel then it causes increase in BSFC also. Calorific value of biodiesel was $12 \%$ lower than that of diesel. Specific fuel consumption increased with the use of biodiesel which may be attributed due to lower calorific value of biodiesel. Biodiesel is found to have lower specific energy content as compared to diesel. Since biodiesels have lower heating value in comparison to diesel, therefore, BSFC increases with the biodiesel concentration in the blends (Canakci, 2007; Shahabuddin et al., 2013; Um \& Park, 2010).

\section{Exhaust Gas Temperature (EGT)}

EGT indicates the exhaust gase temperature which comes out of the engine indicating the combustion effectiveness and conversion of thermal energy in an engine. The amount of energy released was found to indicate combustion temperature. EGT was found to be measured $30 \mathrm{~mm}$ distant from the combustion chamber which indicates combustion temperature. EGT of B20 was found to be nearly same as that of diesel fuel. Lowest EGT was investigated with the use of diesel as compared to biodiesel blends at low speeds. This is due to oxygenated nature of biodiesel causing proper combustion (El- Kasaby \& Nemit-allah, 2013). The researchers also investigated that different types of biodiesel blends did not make any difference in EGT. The general trend is that EGT increases with load. Researchers investigated that operating parameters of the engine which causes lower BSFC and higher BTE also causes lower EGT. Researchers investigated that increase in biodiesel concentration in blends cause increase in EGT. EGT of B20, B40, B60, B80 and B100 were found to be higher by $2.3 \%, 6.3 \%, 8.7 \%, 11.3 \%$ and $14 \%$ respectively as compared to that of diesel fuel. It would also be reported that there is $5^{\circ} \mathrm{C}$ increase in EGT with a $20 \%$ increase in biodiesel concentration in 
blend fuels which may be due to increase in heat losses in fuel blends. EGT of diesel were investigated to be $131^{\circ} \mathrm{C}, 160^{\circ} \mathrm{C}, 186^{\circ} \mathrm{C}$, $212^{\circ} \mathrm{C}$ and $240^{\circ} \mathrm{C}$ whereas EGT of B100 biodiesel were investigated to be $152^{\circ} \mathrm{C}, 182^{\circ} \mathrm{C}, 211^{\circ} \mathrm{C}, 243^{\circ} \mathrm{C}$ and $272{ }^{\circ} \mathrm{C}$ at $0 \%, 25 \%, 50 \%$, $75 \%$ and $100 \%$ load respectively. Similar findings were reported by other researchers also (Raheman \& Ghadge, 2008). Increase in engine efficiency causes reduction in exhaust energy. It was also investigated that decrease in adiabatic flame temperature was one of the reason for the decrease in EGT (Jacobs, 2015).

\section{Mechanical Efficiency}

Mechanical efficiency is the ratio of brake work at the crankshaft to indicated work in the combustion chamber of an engine (Mohite et al., 2016). Mechanical efficiency is also known as the ratio of brake power to the sum of brake power and friction power. Some portion of the indicated work is found to be used to expel exhaust gases, induct fresh air and also to overcome friction of piston, bearings and other mechanical components of the engine. Thus mechanical efficiency is found to measure the ability of the diesel engine to overcome the loss due to friction power.

\section{Volumetric Efficiency}

The effectiveness of induction process in an engine is found to comprise of the intake manifold, air filter, intake valve and is measured by volumetric efficiency. Four stroke engines have separate induction systems and therefore, volumetric efficiency is applicable in four stroke engines.Volumetric efficiency of a diesel engine is the ratio of actual consumption to theoretical consumption of air. Volumetric efficiency is closely related to exhaust gas temperature. Higher exhaust gas temperature causes rise in retained gas temperature, which results in the increase in temperature of incoming fresh air. The actual consumption of air is found to be inversely proportional to the density of air. Density of air will be lower at higher temperature. Volumetric efficiency is also found to be reduced with increase in brake power. This is due to reduction in air fuel ratio with an increase in brake power. The maximum amount of air input into the cylinder during each cycle is found to determine the power and performance of an engine. The higher the quantity of air input, higher quantity of fuel could be burned with higher energy conversion into power output. Density of atmospheric air multiplied by swept volume is the mass of air which should be consumed for each cycle in an engine ideally. Volumetric efficiency is found to measure the effectiveness of the induction process of an engine. Rise of temperature of incoming fresh air is found in the cylinder due to higher EGT. Biodiesel concentration in blends causes reduction in the density of incoming fresh air due to rise in temperature. This increases the actual consumption of air causing an increase in volumetric efficiency (Mohite et al., 2016).

\section{Air- Fuel Ratio}

Air fuel ratio may be defined as the ratio of air flow rate to fuel mass flow rate in an engine. Air fuel ratio influences the quality of emission. This ratio should be in the combustible range for proper combustion.

\section{Unburned Hydrocarbon Emission}

$\mathrm{HC}$ emission act as irritants and odorants in the atmosphere. Some portions of $\mathrm{HC}$ emissions react with atmospheric gases to form photochemical smog. Photochemical smog is not desirable. Diesel engines have only $20 \%$ of HC emissions in comparison to petrol engine. The reason is that the diesel engine operate with lean fuel air mixture. HC emissions are directly proportional to fuel- air mixture. Large amount of HC emissions are emitted with rich fuel air mixture. This is due to lack of oxygen to react with all the carbon with the use of rich fuel air mixture (Pulkrabek, 2003). There is a significant reduction in $\mathrm{HC}$ emission with the use of biodiesel as compared to that of diesel. A minimum of 33ppm HC emission was reported with the use of B30 biodiesel blend indicating that $\mathrm{HC}$ emission reduces with the increase in biodiesel concentration in fuel blends at $\mathrm{CR}$ of 18 . This may be due to higher temperature and pressure at higher compression ratio. This may also be due to addition of oxygenate fuels. Oxygen enrichment is found to favour $\mathrm{HC}$ oxidation in the expansion and exhaust process. The reduction in $\mathrm{HC}$ emission was investigated to be linear with the addition of biodiesel in blends. The higher and lower values of HC produced were reported to be $0.0299 \mathrm{~g} / \mathrm{kWh}$ and $0.01554 \mathrm{~g} / \mathrm{kWh}$ respectively which were found to be lower than that of Euro Norms-IV i.e. $0.5 \mathrm{~g} / \mathrm{kWh}$ (Huang et al., 2005; Muralidharan \& Vasudevan, 2011; Sivaramakrishnan \& Ravikumar, 2014). HC emission was investigated to be decreased with the use of biodiesel blends as compared to that of diesel. This is due to effective oxidation which is caused by presence of excess oxygen in biodiesel (Ramalingam et al., 2018).

\section{Carbon Monoxide Emission}

Emission of carbon monoxide is not desirable and it also represent loss of chemical energy which are not fully used in engine (Pulkrabek, 2003).Diesel engine operates with overall lean mixture and therefore, it has very low CO emission as compared to petrol engine. Chemical energy which is not fully utilised to develop power output in engine, is lost and may be represented by the $\mathrm{CO}$ emission. A significant reduction in $\mathrm{CO}$ emission was found at all engine speed with the use of biodiesel blends. This is due to higher oxygen content in biodiesel as compared to that of diesel, which causes proper combustion thereby reducing the $\mathrm{CO}$ emission. Combustion process is found to be accelerated by fuel based oxygen (Hosseini et al., 2017). Researchers investigated the $\mathrm{CO}$ reduction with increase in brake power at all loads. $\mathrm{CO}$ emission is reported to be lower for biodiesel blends as compared to that of diesel which may be attributed due to presence of excess oxygen in biodiesel (Ramalingam et al., 2018). CO emission was reported to be decreased with the use of biodiesel blends as compared to that of diesel fuel. This is due to oxygen content in biodiesel. This is due to lower $\mathrm{C} / \mathrm{H}$ ratio of biodiesel as compared to that of diesel. It is also found that decrease in $\mathrm{CO}$ is not dependent on biodiesel concentration in blends (Rajaraman et al., 2009). 


\section{Nitrogen Oxide Emission}

Oxides of nitrogen are found to be present in exhaust gases of an engine. They contain major part of Nitric oxide (NO) with minor part of Nitrogen dioxide $\left(\mathrm{NO}_{2}\right)$ and small amount of other oxides of nitrogen. The $\mathrm{NO}_{\mathrm{x}}$ emission also causes photochemical smog which is not desirable (Pulkrabek, 2003). During combustion process, NOx are produced in the combustion chamber due to the chemical reaction between atomic oxygen and nitrogen. Chemical reactions which produces NOx are dependent on temperature at the time of reaction and therefore, NOx emissions are minimum at lower loads. Higher amount of NOx was found to be emitted with the use of biodiesel blends at all engine speeds. Higher NOx emission was found with the use of biodiesel blends due to the following reasons (El- Kasaby \& Nemit-allah, 2013):

1. Higher adiabatic flame temperature of biodiesel causes complete combustion which results in higher temperature and NOx emission. Quantity of double bonded molecules are higher in biodiesel as compared to diesel. Adiabatic flame temperatures of these double bonded molecules are higher resulting in increase in NOx emission for biodiesel.

2. Oxidation of nitrogen results in the formation of NOx in combustion chamber. The NOx formation rate was found to be a function of flame (combustion) temperature, stay time of nitrogen at the temperature and oxygen content in the combustion chamber. At high flame temperature, there would be dissociation of nitrogen $\mathrm{N}_{2}$ and oxygen $\mathrm{O}_{2}$ into atomic states in the combustion chamber which is found to be participated in a number of reactions. There are three principal reactions resulting in production of NOx according to Zeldovich mechanism:

$$
\begin{aligned}
& \mathrm{N}_{2}+\mathrm{O}---\rightarrow \mathrm{NO}+\mathrm{N} \\
& \mathrm{N}+\mathrm{O}_{2}--\rightarrow \rightarrow \mathrm{NO}+\mathrm{O} \\
& \mathrm{N}+\mathrm{OH}-\rightarrow \mathrm{NO}+\mathrm{H}
\end{aligned}
$$

$\mathrm{NO}_{\mathrm{x}}$ was reported to be increased with load for all test blend fuels. This is due to more quantity of fuel injection and their combustion in the cylinder with increase in engine load resulting in higher gas temperature and consequently more $\mathrm{NO}_{x}$ formation (Rajaraman et al., 2009).

\section{Brake Specific Energy Consumption (BSEC)}

It is the product of brake specific fuel consumption and calorific value. Therefore, BSEC is one of the important parameter to evaluate the performance characteristics because it takes into account the calorific value of fuels in blends. It includes the brake specific fuel consumption and calorific value of blend fuel. BSEC may also be defined as the energy input, which is needed to produce unit brake power. Therefore, BSEC has been chosen as a key parameter for an energy audit of diesel engine fuelled with a biodiesel blend fuel. It also facilitates the proper evaluation of blend fuels as its capability to run a diesel engine (Fattah et al., 2014; Imtenan et al., 2015). Reduction in BSEC is observed with increase in load due to reduction in brake specific fuel consumption at higher loads. Increase in BSEC is observed respectively with the increase in the biodiesel concentration in blend fuel. This may be caused due to dependence of BSEC on BSFC directly as it is a product of calorific value and brake specific fuel consumption (Mohite et al., 2016 d). Researchers investigated increase in BSEC with the use of biodiesel blends. An increase of $20.21 \%$ higher than that of diesel for BSEC was reported with the use of JB 100 at $1200 \mathrm{rpm}$. Increase of $2.68 \%, 5.84 \%$ and $13.31 \%$ in BSEC were observed for KB 20, KB50 and KB 100 respectively as compared to diesel at $2200 \mathrm{rpm}$. Similarly, an increase in BSEC of $2.86 \%, 6 \%$, $12.37 \%, 2.59 \%, 5.84 \%$ and $13.31 \%$ as compared to diesel, were reported for JB 20, JB 50, JB100, PB20, PB 50 and PB 100 respectively at rated speed. PB20 fuel was found to be the best BSEC as it has a minimum increment of BSEC (2.59\%) at rated speed in comparison to all test fuels. Higher biodiesel concentration in blend fuels causes an increase in BSEC which may be caused due to lower calorific value of biodiesel blends as compared to diesel (Sahoo et al., 2009). BSEC may indicates the engine's efficiency with which the input fuel energy is used during combustion. BSEC reduction indicates proper use of chemical energy of fuel into useful work output. Combustion quality may be represented as depleted by an increase in BSEC (Paul et al., 2017). Specific energy consumption is the energy amount which is required to develop unit power. Fuels with different calorific values can be compared with this parameter. BSEC is directly proportional to the calorific value of fuel and the fuel injected into the combustion chamber. Researchers investigated decrease in BSEC with the increase in load from $0 \%$ to $100 \%$. BSEC of the engine was found to be higher at lower load and was found to be decreased with an increase in load (Babu \& Anand, 2017; Senhur et al., 2017).

\section{Heat Flow Analysis}

Heat flow analysis is one of the key factor to find out the heat energy's utilisation and wastages. Major factors of heat energy consumption are brake power output, coolant medium, exhaust gas and radiation. Energy crisis and global warming endanger the peaceful existence of human being. This problem can be solved with the increase in dependency on alternative fuels and also minimize energy losses. In this view, thermal balance study in an engine with the use of different biodiesel is fruitful. All energy flows in and out of the engine have been shown with the help of thermal balance. Researchers reported an increase in heat loss to cooling water and heat loss to lubricating oil whereas heat to engine brake power, heat loss to exhaust and heat loss to radiation (unaccounted) were found to be reduced with the increase in the biodiesel concentration in blend as compared to diesel. Thermal balance sheet of the energy and mass inflows and outflows should be drawn to get the inside picture of the system in an easy way. This is called as energy balance or heat balance which is basic analysis of the first law of thermodynamics (Abedin et al., 2015). This study is also useful to test efficiencies due to change in engine design of injectors, pumps, valves, intercoolers and other advanced technologies. Researchers reported that energy balance measurement was required to be analysed on the basis of energy distribution in comparison to direct measurement of fuel energy input due to high uncertainty of fuel energy content i.e. $7 \%$. Therefore, the amount of energy distributed in different parts of the engine was measured and compared on a percentage basis instead of the amount of energy input by fuel. Therefore, direct energy balance between diesel and biodiesel fuels can be compared. This permitted the uncertainties of the results which were required to be small and based primarily on the accuracy of 
measurement equipment (Wallace \& Kremer, 2008). About 35\% of the total chemical energy of the fuel converts into useful work output and $30 \%$ of chemical energy of fuel is lost by the exhaust gases in the form of chemical energy and enthalpy in an engine. The remaining $1 / 3^{\text {rd }}$ of fuel energy may be dissipated to the surrounding. At the time of combustion, temperature upto and above $2700 \mathrm{~K}$ may reach in the combustion chamber of an engine and materials of the engine causes failure due to this much higher temperature, if proper heat transfer does not occur. But it is also necessary to operate an engine as hot as possible to get higher thermal energy (Pulkrabek, 2003). Diesel and biodiesel fuels have different physical properties which affect the characteristics of heat release (Shahabuddin et al., 2013).

With the use of Rice oil biodiesel, the total heat release was reported to be reduced as compared to diesel (Um \& Park, 2010). An advanced knowledge of energetic potentiality and exhaust emission of biodiesel is required with the increase in the alternative fuel use. Energy and exergy analyses were performed to assess the distribution of energy and also for the characterisation of waste heat energy in diesel engine (Magno et al., 2015).

It was investigated that two third of energy of input fuel was lost to exhaust gas and cooling medium. Distribution of fuel energy supplied to the engine is given by the first law of thermodynamics and it also helps to identify the losses which are avoidable. The exergy concept is introduced with the improvement of energy analysis by the second law of thermodynamics. Suitable engine operating conditions identify to perform energy and exergy analysis of diesel engine under mapping characteristics. There are some studies which deal with energy and exergy analysis of diesel engine, but detailed research is not available for all ranges of engine operation. Development of diesel engine based on cogeneration systems at different engine speeds and loads can be increased with the knowledge of energy flow at different operating conditions (Abusoglu \& Kanoglu, 2008; Fu et al., 2013; Magno et al., 2015; Ozkan et al., 2013). Combustion energy is converted into useful work with the release of some of its portions into exhaust gas and cooling medium. Lubricating oil also carries a small amount of heat energy which is found to be negligible. Heat radiation and friction losses in diesel engine are responsible for the loss of remaining part of the combustion energy. According to the second law of thermodynamics, some part of heat loss can be utilized for the enhancement in efficiency of diesel engines (Magno et al., 2015). Energy analysis is used to design engine properly to reduce energy losses. Researchers found out various losses such as heat loss to cooling water, exhaust gas and other miscellaneous losses to reduce losses for the higher power output (Madheshiya \& Vedrtnam, 2018). Researchers investigated change of 37\% of input energy into mechanical energy and loss of $63 \%$ of input energy in different ways (Khoobbakht et al., 2016). Researchers investigated similar energetic performance of biodiesel and diesel in diesel engine. Input heat energy was distributed as $37.4 \%$ to coolant, $31.1 \%$ to exhaust and $29.6 \%$ to useful power output with the use of biodiesel. Input heat energy was distributed as 37.5\% to coolant, $31.4 \%$ to exhaust and $29.2 \%$ to useful power output with the use of diesel in diesel engine. Nominal disparities of $-0.1 \%,-0.3 \%$ and $0.4 \%$ were investigated respectively between diesel and biodiesel with their use in diesel engine. Researchers investigated the energy balance study to monitor the quantity of energy used in a diesel engine with diesel and biodiesel fuel with the measurement of energy output and losses in diesel engine. The aim of the research is to authenticate the functionality of the diagnostic system, find the different ways of energy transfer for fuels in a diesel engine and to use heat transfer modes of conduction, convection and radiation to determine energy transfer and also to design a controlled and instrumented energy management system properly (Wallace \& Kremer, 2008). Similar energetic performance in terms of fuel energy input, brake thermal efficiency, combustion efficiency, heat loss and exhaust loss were reported with the use of biodiesel and their blends as compared to diesel. The difference in heat loss, exhaust loss and brake power output were reported to be $+2.3 \%,-2.9 \%$ and $0.6 \%$ with the use of pure biodiesel as compared to diesel in diesel engine respectively (Canakci \& Hosoz, 2006). It is required to focus on the decrease of heat losses under different operating conditions to improve engine performance. Researchers investigated that heat losses in diesel engine was found to be more with the use of biodiesel as compared to diesel in the study of energy balance in diesel engine (Ramadhas et al., 2006). Researchers conducted experimental study of heat balance and reported that losses in diesel engine were found to be higher with the biodiesel use (Benjumea et al., 2009). Researchers investigated that heal loss to cooling water and lubricating oil were reported to be higher with biodiesel as compared to that of diesel. This is because of proper combustion of biodiesel fuel. Loss of heat to cooling medium was found to be higher in the range of $1 \%$ to $3 \%$ and heat loss to lubricating oil was found to be in the range of $1 \%$ to $2 \%$ with the addition of $5 \%$ to $10 \%$ biodiesel in diesel as blend fuel. It was also investigated that heat loss to exhaust gas was found to be higher with the use of diesel in comparison to biodiesel blends. This may be due to higher concentration of $\mathrm{HC}$ and $\mathrm{CO}$ emission with the use of diesel fuel as compared to that of biodiesel blends. Researchers investigated change of $22.56 \%$ of input energy into usefuel work, $24.47 \%$ of heat loss to cooling water, $21.04 \%$ of heat loss to lubricating oil and $18.9 \%$ of heat loss to exhaust with the use of B10 biodiesel blend fuel. If this was compared with B20 blend, change of heat into brake power was slightly reduced, heat loss to cooling water \& lubrication oil were increased whereas heat loss to exhaust and unaccounted heat loss were reduced. It was also found that $23.72 \%$ of input fuel energy was change into useful brake power with the diesel use. This was due to higher heating value and lower viscosity of diesel as compared to that of biodiesel blends (Abedin et al., 2015). In this respect, heat energy consumption to useful power, its losses to cooling medium, exhaust gases and radiation would be taken into account while analyzing energy audit.

\section{Friction Power}

Lubricity reduces friction causing an increase in mechanical efficiency. Researchers investigated decrease in wear with the biodiesel use in blend fuel. Researchers also investigated decrease in the coefficient of friction with the increase in biodiesel concentration in blend (Fazal et al., 2014). Researchers conducted experiments on an engine with a B15 blend of Palm biodiesel in diesel fuel for $300 \mathrm{~h}$ and reported that B15 exhibited decreased in wear as compared to that of diesel (Kalam \& Masjuki, 2002). Researchers also investigated decrease in wear and friction for short term use. Biodiesel was found to provide better lubricity resulting in reduced wear as compared to diesel during short term tests (Sundus et al., 2017). Sliding parts of diesel engine produces friction which causes reduction in the reliability of engine parts. Different techniques are being used to decrease friction 
Table 2. Effect of energy audit parameters

\begin{tabular}{lll}
\hline Parameter & Importance of parameter & Effects on other parameters \\
\hline BSEC & $\begin{array}{l}\text { BSEC may also be defined as the energy input, which is found to produce } \\
\text { unit brake power. BSEC facilitates correct evaluation of diesel engine } \\
\text { with blended fuel having different densities and calorific values. }\end{array}$ & $\begin{array}{l}\text { It is found to consider BSFC and calorific value of blend } \\
\text { fuel. }\end{array}$ \\
\hline HBP & $\begin{array}{l}\text { HBP means brake thermal efficiency as it represents the change of the } \\
\text { amount of fuel energy to useful work i.e. brake power from total fuel } \\
\text { energy. }\end{array}$ & Brake thermal efficiency \\
& HJW is found to represent the amount of fraction of heat energy which is & This is found to represent the increase in temperature of \\
& lost in cooling medium. & $\begin{array}{l}\text { combustion chamber, cylinder and the whole diesel } \\
\text { engine. It is also found to effect brake thermal efficiency. }\end{array}$ \\
& HEgas is found to represent the amount of fraction of heat energy which & EGT, Volumetric Efficiency, A/F Ratio, BTE \\
\hline HEgas & is lost in exhaust gas. & Brake thermal efficiency \\
\hline HRAD & HRAD is found to represent the quantity of fraction of heat energy which & \\
\hline Friction & Th lost in radiation and also in unaccounted losses. & This power is found to be used in the friction between moving parts of the Mechanical Efficiency \\
Power & engine, draw fresh air into the intake system and to the engine & \\
\hline Smoke & Smoke opacity is found to be a measurement of smoke and soot. & HRAD \\
opacity & &
\end{tabular}

such as coatings, texturing, lightweight use of materials and lubricity improvement. The most important parameter is found to be lubricity to increase engine life. Lubrication is necessary to decrease friction in sliding parts of engine. Lubricity of fuel depends on quantity of viscosity. Presence of fatty acid in biodiesel causes a lubricating thin film which causes decrease in frictional coefficient (Mosarof et al., 2016). Researchers conducted four ball wear tests under $40 \mathrm{~kg}$ load for $1 \mathrm{~h}$ at the speed of $600 \mathrm{rpm}$ to $1500 \mathrm{rpm}$ to compare lubricity of diesel, biodiesel and its blends. Reduction in wear and friction was found with the increase of biodiesel concentration in blend fuel. Wear of steel ball was found to be decreased by $10 \%$ with the use of B20 blend fuel at $1500 \mathrm{rpm}$ speed. Wear was found to be decreased further with increase in concentration of biodiesel in blend fuel and it was found that the wear was decreased by $20 \%$ with the use of B100 biodiesel fuel as compared to that of diesel (Fazal et al., 2013, 2014).

\section{Smoke Emission}

Radiation by soot was found to be a source of losses in efficiency of engines. The soot was found to be luminous during combustion and it was found to be an important source of radiation (Benajes et al., 2015). Smoke opacity increase with load due to increase in fuel consumption. Smoke opacity reduces due to the oxygen in biodiesel as compared to that of diesel. Biodiesel is found to have lower carbon to hydrogen ratio and lack of aromatic compounds as compared to diesel. The higher quantity of oxygen and lower quantity of carbon decreases the smoke formation resulting in reduction of smoke opacity. On the other hand, high sulphur content results in increase in smoke opacity of diesel. Soot concentration increased with load. Soot concentration was found to be reduced with the use of biodiesel blend fuels as compared to that of diesel fuel. This is due to absence of aromatic compounds, sulphur and presence of oxygen in biodiesel, which results in proper combustion of fuel (Rajaraman et al., 2009). With the use of biodiesel, smoke opacity was found to be approximately $22.5 \%$ decreased as compared to that of diesel (Ozsezen \& Canakci, 2010). Similar trends were reported by various researchers. Reductions of $28.6 \%, 50 \%, 62 \%$ and $74 \%$ in PM emissions were reported with the use of $\mathrm{B} 10, \mathrm{~B} 20, \mathrm{~B} 50$ and $\mathrm{B} 100$ biodiesel blends respectively. This is because of higher oxygen content, lower or no sulphur and aromatic content and lower carbon content of biodiesel, which causes reduction in PM emission as compared to that of diesel (Hasan and Rahman, 2017). 87.7\% arguments of researchers investigated that biodiesel causes decrease in PM emission as compared to that of diesel. Researchers also investigated significant decrease in smoke of the range of $50 \%$ to $72.73 \%$ with the use of 8 types of biodiesel fuels as compared to that of diesel. There was a remarkable reduction in PM emission with the increase in biodiesel concentration in blend (Xue et al., 2011). The high temperature burned gases and the soot particles are found to be sources of radiation in the diesel engine (Heywood, 2012). Thus, it is found that smoke is more harmful and it also helps to increase heat loss to radiation. Therefore, this characteristic must be chosen as a key parameter in the Energy Audit as compared to other emission parameter. Thus, increase in smoke emission causes increase in heat loss to radiation. Thus, emission of smoke is directly proportional to heat loss.

Out of all these above parameters, the important parameters have been chosen based on their effective influence on other parameters and are listed in energy audit at initial stage. These important parameters are shown in Table 2.

\section{CONCLUSIONS}

Energy audit can be chosen as one of the methodology to evaluate the feasibility of biodiesel blends as fuel. The selection of performance and emission characteristics for energy audit of diesel engine fuelled with biodiesel blends is one of the important aspect. In this review and analysis, brake specific energy consumption, heat flow analysis which consists of heat utilization in brake power, losses of heat to the cooling water, exhaust gas and radiation, friction power and smoke emission have been chosen as important performance and emission characteristics which should be included in energy audit of diesel engine fuelled with biodiesel blends. This selection is based on their effect on other parameters. This energy audit shall be standardized to harmonize biodiesel research as fuel. 


\section{REFERENCES}

Abedin, M. J., Masjuki, H. H., Kalam, M. A., Sanjid, A., \& Rahman, S. M. A. (2015). Thermal balancing of a multi-cylinder diesel engine operating on diesel, B5 and palm biodiesel blends. Journal of Clean Energy Technologies, 3(2), 115-118. https://doi.org/10.7763/JOCET.2015.V3.178

Abusoglu, A., \& Kanoglu, M. (2008). First and second law analysis of diesel engine powered cogeneration systems. Energy Conversion and Management, 49, 2226-2031. https://doi.org/10.1016/j.enconman.2008.02.012

Avina, J. M., \& Rottmayer, S. P. (2016). Virtual audits: the promise and the reality. Energy Engineering, 113(6), $34-52$. https://doi.org/10.1080/01998595.2016.11772067

Audin, L. (2002). How long since your last energy audit. Strategic Planning for energy and Environment, 22(1), 72-75. https://doi.org/10.1080/10485230209509606

Avina, J. (2013). How to avoid energy audit disasters: a guide to picking a quality energy auditor. Energy Engineering, 110(6), 7-12. https://doi.org/10.1080/01998595.2013.10753692

Aydin, H., \& Bayindir, H. (2010). Performance and emission analysis of cottonseed oil methyl ester in a diesel engine. Renewable Energy, 35, 588-592. https://doi.org/10.1016/j.renene.2009.08.009

Babu, D., \& Anand, R. (2017). Effect of biodiesel-diesel-n-pentanol and biodiesel-diesel-n-hexanol blends on diesel engine emission and combustion characteristics. Energy, 133, 761-776. https://doi.org/10.1016/j.energy.2017.05.103

Bases, G. J. (2004). An energy audit that saved real energy and money, Proceedings of NAWTEC $12,12^{\text {th }}$ North American Waste to Energy Conference, May 17-19, 2004, Savannah, Georgia, USA, NAWTEC 12-2221.

Bazari, Z. (2007). Ship energy performance benchmarking/ rating; methodology and application. Journal of Marine Engineering and Technology, 6(1), 11-18. https://doi.org/10.1080/20464177.2007.11020197

Bellarmine, G. T., \& Arokiaswamy, N. S. S. (1996). Energy management techniques to meet power shortage problems in India. Energy Conversion and Management, 37(3), 319-328. https://doi.org/10.1016/0196-8904(95)00181-6

Belussi, L., Danza, L., Salamone, F., Meroni, I., Galli, S., \& Svaldi, S. D. (2017). Integrated smart system for energy audit: methodology and application. Energy Procedia, 140, 231-239. https://doi.org/10.1016/j.egypro.2017.11.138

Benajes, J., Martin, J., Garcia, A., Villalta, D., \& Warey, A. (2015). Incylinder soot radiation heat transfer in direct injection diesel engine. Energy Conversion and Management, 106, 414-427. https://doi.org/10.1016/j.enconman.2015.09.059

Benjumea, P., Agudelo, J., \& Agudelo, A. (2009). Effect of altitude and palm oil biodiesel fuelling on the performance and combustion characteristics of a HSDI diesel engine. Fuel, 88, 725-731. https://doi.org/10.1016/j.fuel.2008.10.011

Bennett, M., \& Newborough, M. (2001). Auditing energy use in cities. Energy Policy, 29, 125-134. https://doi.org/10.1016/S03014215(00)00108-7

Boharb, A., Allouhi, A., Saidur, R., Kousksou, T., Jamil, A., Mourad, Y., \& Benbassou, A. (2016). Auditing and analysis of energy consumption of an industrial site in Morocco. Energy, 101, 332-342. https://doi.org/10.1016/j.energy.2016.02.035

Braquet, L. (1999). Three levels of energy audits (pre-contract considerartions). Strategic Planning for Energy and the Environment, 19(1), 28-36. https://doi.org/10.1080/10485236.1999.10530576

Canakci, M. (2007). Combustion characteristics of a turbocharged DI compression ignition engine fueled with petroleum diesel fuels and biodiesel. Bioresource Technology, 98, 1167-1175. https://doi.org/10.1016/j.biortech.2006.05.024

Canakci, M., \& Hosoz, M. (2006). Energy and Exergy analyses of a diesel engine fuelled with various biodiesels. Energy Sources Part B: Economics, Planning and Policy, 1(4), 379-394. https://doi.org/10.1080/15567240500400796

Cardenas- Lailhacar, C., Schaub, D., Venkat, S., Capehart, B. L., Capehart, L. C., \& Pawlik, K. E. (2005). A case study for energy auditing using an interactive energy balance. Strategic Planning for Energy and the Environment, 25(1), 34-62. https://doi.org/10.1080/10485230509509679

Dall, G., Speccher, A., \& Bruni, E. (2012). The green energy audit, a new procedure for the sustainable auditing of existing buildings integrated with the LEED Protocols. Sustainable Cities and Society, 3, 54-65. https://doi.org/10.1016/j.scs.2012.02.001

Dincer, I. (1999). Environmental impacts of energy. Energy Policy, 27, 845-854. https://doi.org/10.1016/S0301-4215(99)00068-3

Eisenberg, M. (2012). That's a bright idea! Using USEPA's energy use assessment tool to control costs. Journal (American Water works Association), 104(12), 20-84.

EL-Kasaby, M., \& Nemit-allah, M.A. (2013). Experimental investigations of ignition delay period and performance of a diesel engine operated with Jatropha oil biodiesel. Alexandria Engineering Journal, 52, 141-149. https://doi.org/10.1016/j.aej.2012.12.006

Erkut, E., \& Maclean, D. (1992). Alberta's energy efficiency branch conducts transportation audits. Interfaces, 22(3), 15-21. https://www.jstor.org/stable/25061618

Fattah, I. M. R., Masjuki, H. H., Kalam, M. A., Wakil, M. A., Ashraful, A. M., \& Shahir, S. A. (2014). Experimental investigation of performance and regulated emissions of a diesel engine with Calophylum inophyllum biodiesel blends accompanied by oxidation inhibitors. Energy Conversion and Management, 83, 232-240. https://doi.org/10.1016/j.enconman.2014.03.069

Fazal, M. A., Haseeb, A. S. M. A., \& Masjuki, H. H. (2014). A critical review on the tribological compatibility of automotive materials in Palm biodiesel. Energy Conversion and Management, 79, 180-186. https://doi.org/10.1016/j.enconman.2013.12.002 
Fazal, M. A., Haseeb, A. S. M. A., \& Masjuki, H. H. (2013). Investigation of friction and wear characteristics of Palm biodiesel. Energy Conversion and Management, 67, 251-256. https://doi.org/10.1016/j.enconman.2012.12.002

Fu, J., Liu, J., Feng, R., Yang, Y., Wang, L., \& Wang, Y. (2013). Energy and exergy analysis on gasoline engine based on mapping characteristics experiment. Applied Energy, 102, 622-630. https://doi.org/10.1016/j.apenergy.2012.08.013

Gong, Z. X., Stanovsky, J., \& Mujumdar, A. S. (2011). Energy audit of a fibreboard drying production line using Simprosys software. Drying Technology, 29(4), 408-418. https://doi.org/10.1080/07373937.2010.498069

Hasan, M. M., \& Rahman, M. M. (2017). Performance and emission characteristics of biodiesel-diesel blend and environmental and economic impacts of biodiesel production: a review. Renewable and Sustainable energy Reviews, 74, 938-948. https://doi.org/10.1016/j.rser.2017.03.045

Hansen, S. J. (1999). Investment Grade energy audits. Cogeneration and Competitive Power Journal, 13(3), 63-70. https://doi.org/10.1080/10668683.1999.10530346

Heywood, J. B. (2012). Internal Combustion Engine Fundamentals. India: Tata McGraw Hill Edition.

Hosseini, S. H., Taghizadeh-Alisaraei, A., Ghobadian, B., \& Abhaszadeh-Mayvan, A. (2017). Performance and emission characteristics of a $\mathrm{Cl}$ engine fuelled with carbon nano-tubes and diesel -biodiesel blends. Renewable Energy, 111, $201-213$. https://doi.org/10.1016/j.renene.2017.04.013

Huang, Z., Lu, H., Jiang, D., Zeng, K., Liu, B., Zhang, J., \& Wang, X. (2005). Performance and emission of a Cl engine fueled with diesel/oxygenate blends for various fuel delivery advance angles. Energy Fuels, 19, 403-410. https://doi.org/10.1021/ef049855d

Imtenan, S., Masjuki, H. H., Varman, M., Fattah, I. M. R., Sajjad, H., \& Arbab, M. I. (2015). Effect of n-butanol and diethyl ether as oxygenated additives on combustion emission performance characteristics of a multiple cylinder diesel engine fuelled with diesel - jatropha biodiesel blend. Energy Conversion and Management, 94, 84-94. https://doi.org/10.1016/j.enconman.2015.01.047

Jacobs, T. J. (2015). Waste heat recovery potential of advanced internal combustion engine technologies. Journal of Energy Resources Technology, 137, 1-14. https://doi.org/10.1115/1.4030108

Kalam, M. A., \& Masjuki, H. H. (2002). Biodiesel from palm oil- an analysis of its properties and potential. Biomass Bioenergy, 23, 471-479. https://doi.org/10.1016/S0961-9534(02)00085-5

Kalantzis, F., \& Revoltella, D. (2019). Do energy audits help SMEs to realize energy-efficiency opportunities? Energy Economics, 83, 229-239.https://doi.org/10.1016/j.eneco.2019.07.005

Khan, M. R. B., Jidin, R., \& Pasupuleti, J. (2016). Energy audit data for a resort island in the South China Sea. Data in Brief, 6, 489491. https://doi.org/10.1016/j.dib.2015.12.033

Khoobbakht, G., Akram, A., Karimi, M., \& Najafi, G. (2016). Exergy and energy analysis of combustion of blended levels of biodiesel, ethanol and diesel fuel in a DI diesel engine. Applied Thermal Engineering, 99, 720-729. https://doi.org/10.1016/j.applthermaleng.2016.01.022

Klvac, R., Ward, S., Owende, P. M. O., \& Lyons, J. (2003). Energy audit of wood harvesting system. Scandinavian Journal of Forest Research, 18(2), 176-183. https://doi.org/10.1080/02827580310003759

Knorring, H. V. (2019). Energy audits in shipping companies. Transportation Research Part A, 125, 35-55. https://doi.org/10.1016/j.tra.2019.04.017

Kong, L., Price, L., Hasanbeigi, A., Liu, H., \& Li, J. (2013). Potential for reducing paper mill energy use and carbon dioxide emissions through plant -wide energy audits: a case study in China. Applied Energy, 102, $1334-1342$. https://doi.org/10.1016/j.apenergy.2012.07.013

Koski, M. A. (2002). Compressed air energy audit, the real story. Energy Engineering, 99(3), 59-70. https://doi.org/10.1016/j.tra.2019.04.017

Lucchi, E. (2018). Applications of the infrared thermography in the energy audit of buildings: A review. Renewable and Sustainable Energy Reviews, 82, 3077-3090.https://doi.org/10.1016/j.rser.2017.10.031

Madheshiya, A. K., \& Vedrtnam, A. (2018). Energy- exergy analysis of biodiesel fuels produced from waste cooking oil and mustard oil. Fuel, 214, 386-408. https://doi.org/10.1016/j.fuel.2017.11.060

Magno, A., Mancaruso, E., \& Vaglieco, B. M. (2015). Effects of both blended and pure biodiesel on waste heat recovery potentiality and exhaust emissions of a small Cl engine. Energy, 86, 1-11. https://doi.org/10.1016/j.energy.2015.04.092

Mohite, S., Kumar, S., \& Maji, S. (2016). Performance Characteristics of mix oil biodiesel blends with smoke emissions, International Journal of Renewable Energy Development, 5(2), 163-170. https://doi.org/10.14710/ijred.5.2.163-170

Mora, R. G., Paviglianiti, J., Slocomb, R., Mota, A. B., \& Zaidi, M. (2012). Trends on integrity management programs (IMP) and management system (MS) audit and incident findings, Proceedings of the 2012, $9^{\text {th }}$ International Pipeline Conference IPC 2012, Sept 24-28, 2012, Calgony, Alberta, Canada, IPC 2012-90046.

Mosarof, M. H., Kalam, M. A., Masjuki, H. H., Alabdulkarem, A., Ashraful, A. M., Arslan, A., Rashedul, H. K., \& Monirul, I. M. (2016). Optimization of performance, emission, friction and wear characteristics of Palm and Calophyllum biodiesel blends. Energy Conversion and Management, 118, 119-134. https://doi.org/10.1016/j.enconman.2016.03.081

Muralidharan, K., \& Vasudevan, D. (2011). Performance, emission and combustion characteristics of a variable compression ratio engine using methyl esters of waste cooking oil and diesel blends. Applied Energy, 88(11), $3959-3968$. https://doi.org/10.1016/j.apenergy.2011.04.014 
Nabitz, L., \& Hirzel, S. (2019).Transposing The Requirements of the Energy Efficiency Directive on Mandatory Energy Audits for Large Companies: A Policy-Cycle-based review of the National Implementation in the EU-28 Member States. Energy Policy, 125, 548-561. https://doi.org/10.1016/j.enpol.2017.12.016

Niu, M., \& Leicht, R. M. (2016). Information exchange requirements for building walk through energy audits. Science and Technology for the Built Environment, 22(3), 328-336. https://doi.org/10.1080/23744731.2016.1151713

Ozkan, M., Ozkan, D.B., Ozencer, O., \& Yilmaz, H. (2013). Experimental study on energy and exergy analyses of a diesel engine performed with multiple injection strategies; effect of pre-ignition timing. Applied Thermal Engineering, 53, 21-30. https://doi.org/10.1016/j.applthermaleng.2012.12.034

Ozsezen, A. N., \& Canakci, M. (2010). The emission analysis of an IDI diesel engine fuelled with methyl ester of waste frying palm oil and its blends. Biomass and Bioenergy, 34(12), 1870-1878. https://doi.org/10.1016/j.biombioe.2010.07.024

Parker, S. A. (2015). Ideas that works! The midnight audit. Strategic Planning for Energy and the Environment, 35(1), 7-9. https://doi.org/10.1080/10485236.2015.11439120

Paul, A., Panua, R., \& Debroy, D. (2017). An experimental study of combustion, performance, exergy and emission characteristics of a Cl engine fueled by diesel-ethanol-biodiesel blends. Energy, 141, 839-852. https://doi.org/10.1016/j.energy.2017.09.137

Pulkrabek, W. W. (2003). Engineering Fundemantals of the Internal Combustion Engine. University of Wisconsin-Patteville, Prentice Hall, Upper Saddle River, New Jersey, 07458.

Raheman, H., \& Ghadge, S. V. (2008). Performance of diesel engine with biodiesel at varying compression ratio and ignition timing. Fuel, 87, 2659-2666. https://doi.org/10.1016/j.fuel.2008.03.006

Rajaraman, S., Yashwanth, G. K., Rajan, T., Sivakumaran, R., \& Raghu, P. (2009). Experimental investigation of performance and emission characteristics of Moringa oil methyl ester and its diesel blends in a single cylinder direct injection diesel engine, Proc. of the ASME 2009 Inter. mechanical Eng. congress and expo.. IMECE 2009, Nov 13-19, Lake Buena Vista, FL, USA IMECE $2009-11265$.

Ramadhas, A. S., Jayraj, S., \& Muraleedharan, C. (2006). Theoretical modelling and experimental studies on biodiesel fuelled engine. Renewable Energy, 31, 1813-1826. https://doi.org/10.1016/j.renene.2005.09.011

Ramalingam, S., Rajendran, S., \& Ganesan, P. (2018). Performance improvement and exhaust emission reduction in biodiesel operated diesel engine through the use of operating parameters and catalytic converter: a review. Renewable and Sustainable Energy Reviews, 81, 3215-3222. https://doi.org/10.1016/j.rser.2017.08.069

Romero, H., Ambriz, J. J., Ortiz, J. N., \& Sheffield, J. W. (1999). Joint Mexico / USA Energy audit- a case study. Energy Engineering, 96(6), 17-28. https://doi.org/10.1080/01998595.1999.10530478

Sahoo, P. K., Das, L. M., Babu, M. K. G., Arora, P., Singh, V. P., Kumar, N. R., \& Varyani, T. S. (2009). Comparative evaluation of performance \& emission characteristics of jatropha, karanja \& polanga based biodiesel as fuel in a tractor engine. Fuel, 88(9), 1698-1707. https://doi.org/10.1016/j.fuel.2009.02.015

Senhur, S., Asokan, M. A., Rahul, R., Francis, S., \& Sreelekh, M. K. (2017). Performance, emission and combustion characteristics of diesel engine fuelled with waste cooking oil biodiesel/diesel blends with additives. Energy, 122, 638-648. https://doi.org/10.1016/j.energy.2017.01.119

Shahabuddin, M., Liaquat, A. M., Masjuki, H. H., Kalam, M. A., \& Mofijur, M. (2013). Ignition delay, combustion and emission characteristics of diesel engine fueled with biodiesel. Renewable and Sustainable Energy Reviews, 21, 623-632. https://doi.org/10.1016/j.rser.2013.01.019

Sivaramakrishnan, K., \& Ravikumar, P. (2014). Optimization of operational parameters on performance and emissions of a diesel engine using biodiesel. International Jounal of Environmental Science and Technology, 11, 949-958. https://doi.org/10.1007/s13762-013-0273-5

Sundus, F., Fazal, M. A., \& Masjuki, H. H., (2017). Tribology on the biodiesel: a study on enhancing biodiesel stability and its fuel properties. Renewable and Sustainable Energy Reviews, 70, 399-412. https://doi.org/10.1016/j.rser.2016.11.217

Thiruvengadam, A., Pradhan, S., Thiruvengadam, P., Besch, M., \& Carder, D. (2014). Heavy duty vehicle diesel engine efficiency evaluation and energy audit, Center for Alternative Fuels, Engines, and Emissions, West Virgina University, Morgantown, WV, Final report on Oct, 2014 published by Oscar Delgado, the International Council on Clean Transportation, Washington DC.

Thomas, G., O’Doherty, D., Sterling, D., \& Chin, C. (2010). Energy audit of fishing vessels, Proceedings of the Institution of Mechanical Engineers, Part M: Journal of Engineering for the Maritime Environment, 224(2), 87-101. https://doi.org/10.1243\%2F14750902JEME186

Thumann, A., \& Younger, W. (2010). Handbook of energy audit, $7^{\text {th }}$ Edition, Lilburn, GA: the Fairmont Press, Inc.

Turley, R. E., \& Bui, M. (1981). A practicable method to identify the excessive consumer of energy. Interfaces, 11(1), 62-67.

Um, S., \& Park, S.W. (2010). Modeling effect of the biodiesel mixing ratio on combustion and emission characteristics using a reduced mechanism of methyl butanoate. Fuel, 89(7), 1415-1421. https://doi.org/10.1016/j.fuel.2009.10.026

Wallace S. J., \& Kremer G. G. (2008). Diesel engine energy balance study operating on diesel and biodiesel fuels. Proceedings of IMECE 2008, 2008 ASME International Mechanical Engineering Congress an exposition, Oct 31-Nov 6, 2008, Boston, Massachusetts, USA, IMECE 2008-67712.

Xue, J., Grift, T. E., \& Hansen, A. C. (2011). Effect of biodiesel on engine performance and emission. Renewable \& Sustainable Energy Reviews, 15, 1098-1116. https://doi.org/10.1016/j.rser.2010.11.016 